\title{
A Summary of Metacognition Research on Second Language Learning in China
}

\author{
Xiaoting Zhang \\ English Department of Tourism \\ Chengdu Institute Sichuan International Studies University \\ Chengdu, China
}

\author{
Jing Xiao \\ Business English Department \\ Chengdu Institute Sichuan International Studies University \\ Chengdu, China
}

\begin{abstract}
Since the meta-cognitive theory was introduced to the field of language teaching and research in China, many meta-cognitive theory-based researches on English learning and teaching have been carried out. This paper reviews these researches and concludes the achievements as well as the shortcomings: (1) the introduction of meta-cognitive theory to foreign language teaching is later than other fields; (2) the number of studies thrives in recent years, and peaked in 2008 and 2009; (3) the study subjects were mainly the non-English majors; (4) research methods were both subjective speculation, and objective evidence; (5) meta-cognitive abilities of the students were investigated by focusing on the basic language skills; (6) a relatively small number of studies focusing on English majors; (7) low reliability of empirical research caused by a narrow scope of the study; (8) no researches focusing on English majors of independent colleges.
\end{abstract}

Keywords-second language learning; metacognition; research

\section{INTRODUCTION}

In the 1970s, Flavell [1] first proposed the concept of metacognition. He defined metacognition as knowledge about cognition and control of cognition. For example, a person is engaging in metacognition if he notices that he is having more trouble learning A than B; [or] if it strikes him that he should double-check $\mathrm{C}$ before accepting it as fact.. And then in 1979 [2] he published in the "American Psychology" magazine entitled "metacognitive and cognitive monitoring" article, exploring the new areas of cognitive development. Metacognition has developed into a theoretical trend, and meta-cognitive research is not limited to the category of cognitive psychology, instead it was introduced to various fields. In the west, meta-cognitive research on foreign language learning originated in the 1980s. Wenden published papers as early as in 1982, 1983 and 1986, pointing out that the importance of metacognitive strategy for research on foreign language learners' strategy [3]. O'Malley [4], Oxford [5], etc., also classified metacognition in their foreign language learner's strategy classification system and recognized its important position. In the past 14 years, the introduction of advanced theories of foreign

This paper is one of the phased results of the research project of the humanities and social sciences of the Sichuan Provincial Department of Education and the "Research on the Cultivation of Autonomous Learning Ability of English Majors in Independent Colleges" (14SB0524). scholars in foreign language teaching circles has become increasingly rich in meta-cognition in foreign language learning. This paper attempts to systematically sort out these studies to summarize the achievements and shortcomings, to explore the future research direction and to promote the domestic cognitive research on second language learning to a new height, which may make more contributions to China's foreign language education.

\section{AN OVERVIEW OF L2 METACOGNITION RESEARCH}

The author, setting the "metacognition" as the key words, searched eight core journals of Chinese humanities and social science and six other important foreign language journals on the Chinese database "cnki.net". The results showed that before 2000, the related research on metacognition in domestic foreign language circles was blank except two papers. Wu Xia [6] published "non-English majors vocabulary learning strategies" In the "Foreign Language Teaching and Research" and Liu Peihua [7] published "metacognition and foreign language learning" in the "Journal of Sichuan International Studies University". So the search time was set between 2000 and 2013, and 81 relevant research papers were found, as shown in "Fig. 1".

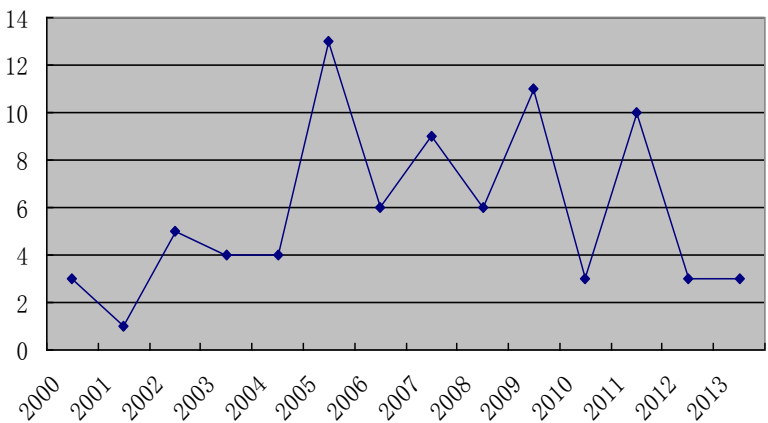

Fig. 1. L2 metacognitive research published in the core and key journals of the foreign language in the past 14 years.

Between 2000 and 2001 only three papers were punished, two of which were theoretical discourse, the third was a case study. These three articles were published in the Enlightenment stage, showing that domestic scholars had begun to think about metacognition study on foreign language learning, and inspiring more scholars to carry out practical research. Since 2002, the number of domestic L2 
metacognitive research has shown an upward trend, and it is most active between 2004 and 2011 which is the development stage.

In the early stage, more studies focused on theoretical summarization. In recent years, researchers paid more attention to the empirical study on foreign language teaching. The quality of research is also improved obviously, especially in listening, reading and writing. Fruitful results provide references for the English teaching from the theory to the actual teaching.

\section{A. Selecting a Template}

First, confirm that you have the correct template for your paper size. This template has been tailored for output on the A4 paper size. If you are using US letter-sized paper, please close this file and download the file "MSW_USltr_format".

\section{B. Maintaining the Integrity of the Specifications}

The template is used to format your paper and style the text. All margins, column widths, line spaces, and text fonts are prescribed; please do not alter them. You may note peculiarities. For example, the head margin in this template measures proportionately more than is customary. This measurement and others are deliberate, using specifications that anticipate your paper as one part of the entire proceedings, and not as an independent document. Please do not revise any of the current designations.

\section{The Present Situation of L2 Metacognition STUDY}

The author studies more than 70 papers and finds that there are two types of research on L2 metacognition at present. One is theoretical argument and the other is experimental research, including investigation, interventional study, diachronic research and case study. 19 papers explore English learning ability and metacognition from the macro point of view, including 7 theoretical research, 12 empirical research; 49 from the micro perspective of metacognition in listening, speaking, reading, writing and other basic skills in "Fig. 2"; 8 articles discuss the relevance of autonomous learning ability and metacognition, and 6 on the vocabulary teaching, advanced English teaching, learning motivation and teachers and other novel perspective.

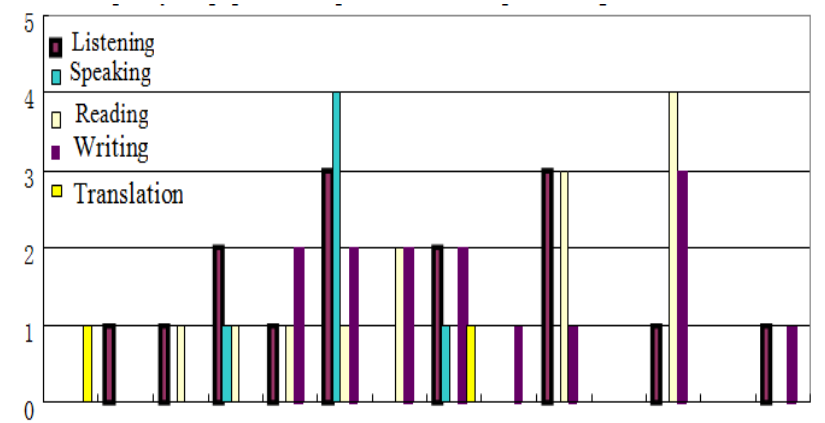

20002001200220032004200520062007200820092010201120122013

Fig. 2. Metaphorical research on foreign language listening, speaking, reading and writing.
"Fig. 2" shows the relevant researches in the field of listening, conversation, reading, and writing and translation skills in the framework of metacognitive theory in the last 14 years. The number is $15,6,12,14,2$ articles respectively. Among them, listening and writing have attracted much attention from domestic scholars. The reason is that metacognitive research in listening, writing and reading of foreign scholars have started early and rich in achievements and this have brought new inspiration and reference to domestic scholars. It is worth mentioning that metacognitive research on spoken language or conversation and translation is relatively rare, especially in the field of translation. The main reason may be that speaking and translation are both comprehensive abilities, involving too many variables, which makes the operation of empirical study difficult.

\section{A. Listening Meta-cognitive Research}

There are 6 theoretical reviews of listening metacognition, 9 empirical studies on metacognitive consciousness and metacognitive strategies. 3 of them use English majors as subjects, and 5 studies use non-English majors as subjects, and one with hearing failure as the object of study, discusses the relationship between metacognitive strategies and hearing success and unsuccessful.

\section{B. Conversational or Speaking Metacognitive Research}

There are 6 meta-cognitive studies, 5 theoretical reviews and an empirical study of oral teaching. Professor Yao Jianpeng has published three metacognitive theories for "session repair" in 2005 [21] and 2012 [22]. The first article reveals the characteristics of self-patching and metacognition at all stages, and corrects the definition of session repair. The second part is based on the real corpus, from the perspective of metacognition analysis and division of the self-repair session; the third, based on the core concept of metacognition, discussed the speaker's self-repair process is a perception of cognitive and metacognitive behavior. Professor Yao's series of studies show that self-repair in oral English has a distinctive metacognitive nature enrich and develop the meta-cognitive theory of Flavell and Nelson et al. for the study of natural speech.

\section{Reading Metacognitive Research}

There are 12 metacognitive studies on reading, 2 in theory and 10 in empirical studies. There are five articles on the metacognitive level of reading.

In the empirical study, Liu Ying [8] conducted ten-week metacognitive strategy training on English sophomore nonEnglish majors with poor English reading level to understand the effectiveness of metacognitive strategies training in college English. Xue Jin [9], based on Flavell meta-cognitive theory framework, used qualitative and quantitative research methods to draw up second language English reading metacognitive evaluation scale. In the experimental class 45 students receive metacognition Training for a period of 16 weeks of to explore the interaction between reading level and metacognitive experience in L2 reading metacognitive training. These two are combined with strategy training to do the longitudinal comparative study. 


\section{Writing Metacognitive Research}

There are 4 theoretical reviews. Tang et al. [10] introduced the achievements of English writing research based on metacognitive theory before and after 2005, and summed up its main contributions, analyzed the topics to be explored in this field and the future research trends. Some scholars have discussed the strategies of using metacognitive knowledge to improve students 'English writing level from meta-cognitive knowledge to students' writing process planning, monitoring and adjustment.

There are 10 articles of empirical study. Among them, Wu Hongyun and Liu Runqing [11], [12] carried out the writing factor analysis through two questionnaires, and deduced and verified the theoretical framework of metacognition of second language writing, and established the model of writing metacognitive structural equation. Wu Hongyun [13] studied the metacognitive teaching experiment with non-English majors, and explored the types of metacognitive experiences and their relationship with them through vertical and horizontal surveys, large-scale questionnaires and essay tests. The relationship between writing achievement and the influence of writing teaching on metacognitive experience were also analyzed.

Han Song [14] found that there is a significant positive correlation between writing metacognitive knowledge level and writing achievement.

$\mathrm{Xu}$ Jinfen [15] conducted a comparative study on the differences in metacognitive knowledge between five English writers and five unsuccessful non-English majors. The results show that writing metacognitive knowledge such as "subject", "task" and "strategy" of writing success is obviously stronger than writing, and the former is in writing strategy Use and writing behavior is also stronger than the latter. Xiao Wuyun [16] chose 80 non-English majors for the test, who were divided into sub-experimental group and control group. The experimental group received metacognitive strategy training, which lasted 36 hours. The descriptive statistics of writing of two groups were collected before and after the training, and reached the conclusion that the writing meta-cognitive strategy training can effectively improve the students' writing achievement.

\section{E. Metacognition in Translation}

Metacognitive research in translation is rather scarce; so far there are only two. Cai Han-song and Guo Jiayue [17], in the case study of psycho-linguistics in English-Chinese translation of double negative sentences, from the perspective of psycholinguistics, investigates the application of metacognitive and cognitive strategies in the process of thinking, and finds that cognitive strategies are mainly used in the first and second stages, and metacognitive strategies, mainly self-regulation, selective attention, in the second and third stages. Tang Jianhe [18] explores the metacognitive consciousness and the monitoring connotation in the process of metacognition. It is believed that the theoretical results of metacognitive research can be borrowed into the field of translation theory and practice. It can be seen that the theoretical framework of translation metacognition has not yet formed, and the research in this field has not been paid more attention by scholars.

\section{F. Correlation Study between Metacognition and Autonomous Learning}

In the course of the study, the author found that many scholars continue to try a new perspective and ideas under the framework of metacognition theory from 2009. 8 articles are empirical researches by combining meta-cognitive with autonomous learning, trying to establish a new autonomous learning model suitable for the needs of English learners.

One is based on a questionnaire survey and does not involve metacognitive strategy training. It is suggested that teachers should increase their knowledge and strategy introduction and training in classroom teaching so as to improve students' assessment and monitoring of independent listening learning.

The other is a comparative study. Longitudinal comparison: Liu Yuhui [19] used Wen Qiufang's "English Learning Strategy Questionnaire" to investigate the metacognitive learning strategies of 93 students from 13 universities in Beijing Polytechnic University and track their online LAN self-learning status. And then the relationship between metacognitive learning strategies and autonomous learning ability and academic performance was analyzed, according to the students' metacognition learning strategy usage, the time of online learning, the number of online tests and the final examinations. Longitudinal and horizontal contrast: Xiao Wuyun [20] takes 60 non-English majors as the research object. The subjects are divided into experimental class and control class. The former metacognitive strategy training is carried out for one year, and the meta-cognitive strategy questionnaire table and level test were used to collect relevant data of two classes before and after training. Two studies have shown that meta-cognitive strategy training can effectively improve students' autonomous learning level and improve students' English achievement.

\section{RESEARCH ACHIEVEMENTS AND IMPLICATIONS} EXISTING PROBLEMS AND FUTURE RESEARCH DIRECTIONS

The results of the domestic study on L2 meta-cognition are summarized as follows:

- Based on the theory of metacognition, this paper discusses the connotation and content of metacognition and metacognitive strategies in English teaching and learning, and discusses the role of metaphor reading and writing and other basic skills to develop and perfect Metacognitive theory proposed by foreign scholars.

- The use of metacognitive strategies is mainly manifested in four aspects: "monitoring plan", "question evaluation", "process monitoring" and "comprehension ". Cognitive strategies are mainly manifested in "retrieval and reproduction" and "problem cognition "Two aspects, indicating that 
different observation variables and individual results have a different degree of correlation between.

- The majority of the metacognitive level survey of new students shows that the level of metacognition of students' English learning is relatively low, and the metacognitive knowledge, metacognitive strategies and metacognitive monitoring training of freshmen should be strengthened. The result of learning and mastering metacognitive strategies can achieve their own achievements.

- The empirical research on metacognitive strategy training shows that metacognitive strategies can effectively improve the learning ability. Metacognitive training introduces the idea of classroom teaching, the related steps and contents are not only feasible, but also necessary for the reform of English teaching in our country.

- Listening comprehension is related to the ability of learner's success. Metacognitive strategies can be divided into three stages: pre-class strategy, classroom strategy and post-class strategy in listening teaching. Self-examination helps students find themselves the weak links and problems in listening. There is a significant correlation between cognitive strategies and listening comprehension and vocabulary acquisition. Strengthening metacognitive training in listening teaching is a necessary and effective way to help students improve their listening level. The study shows that metacognitive strategy training is the best for students with poor listening ability but with standard pronunciation, but the effect on students with poor voice is not obvious.

- Foreign language teaching materials can be written in conjunction with planning, monitoring and evaluation strategies to suit student needs.

- The essence of the generation and application of communicative strategies lies in the monitoring and regulation of cognition. Metacognitive strategies are the main reasons for monitoring and regulating communication. Self-repair in spoken language has a distinctive metacognitive nature.

- Metacognitive strategy plays a great role in English reading. It is found that this high level of cognitive strategies to a certain extent can make up for the lack of vocabulary. The freshmen also lack of reading meta-cognition in reading behavior monitoring. Strengthening the cultivation of adult students' metacognitive ability is an effective way to improve their reading comprehension ability. Learners should combine reading metacognitive strategies and reading classes, rather than simply conducting extracurricular lectures or training. Studies of learners with low reading scores show that short-term strategy training is effective in strengthening metacognition and reading strategies, but makes no significant effect on the improvement in reading scores.
- The metacognitive subject assessment and metacognitive strategies have a direct and important influence on the writing achievement, and the metacognitive task assessment has an indirect effect on the writing achievement. There is a correspondence between writing metacognitive experience and writing achievement. Multivariate regression analysis showed that prior planning and selection attention meta-cognitive strategies were the main influencing factors of English writing.

- The metacognitive consciousness and the monitoring connotation in the process of translation were explored. The theoretical achievements of metacognitive research can be borrowed into the field of translation theory and practice, i.e. how to define the translation strategy and how to implement the conversion from source language to target language.

- Through the combination of training and metacognitive strategies in teaching, the frequency of using metacognitive strategies in reading is obviously increased, and the ability of autonomous learning has been improved. In the autonomous learning, the metacognitive experience can control the emotional factors experienced by the learners in the learning process. The metacognitive monitoring can plan the learners' learning content, the monitoring of the learning process, the examination of the learning progress, the evaluation of the learning effect, Learning feedback and learning strategies to monitor and adjust.

- The establishment of independent learning center is a new attempt to cultivate students' autonomous learning ability. Before the opening of independent learning center, the teaching activities should be appropriate to increase the training content of metacognitive strategies and social strategies. Students understand and learn the necessary learning methods and learning strategies in the autonomous learning center, and cultivate and improve students' awareness of using the autonomous learning center.

- Meta-cognitive training for English learning unsuccessful can greatly improve the use and learning achievement of metacognitive strategies, but the correlation between meta-cognitive strategies and achievement improvement is not Strong, and only a few strategies have a certain interpretation of the results, which means that a variety of factors common, or meta-cognitive strategies indirectly on the results.

- For a qualified teacher, in addition to the basic skills of a discipline, he/she needs to have basic theoretical knowledge of education, psychology and other fields, to apply these theories to their own practice, to acquire the ability of planning and implementation of teaching programs, and adjusting the teaching strategies. 


\section{EXISTING PROBLEMS AND FUTURE RESEARCH DIRECTIONS}

There is no doubt that the study of domestic L2 metacognition has achieved fruitful results, but there are still some shortcomings, such as:

- The research on the metacognitive learning strategies of listening and speaking language skills is very rich, but the meta-cognitive strategies have not made much in-depth research on how much of the skills in the acquisition of skills.

- Meta-cognitive research in oral and translation is still lacking, especially the metacognitive theory framework of translation has not yet been formed.

- There are no breakthroughs in the study of metacognition and metacognitive strategies in speech intonation and grammar learning.

- The study of metacognitive experiments in reading and writing skills is becoming more and more abundant, but in the data analysis, the experimental group and the control group can be designed and the lateral longitudinal contrast training before and after metacognitive strategy training is less.

- The research methods are rich, questionnaires; experimental research, case studies, diachronic studies, but only a few scholars use questionnaire research plus case studies plus experimental research. In addition to the use of the questionnaire most of the lack of reliability and validity of the research and analysis.

- Most of the subjects were non-English majors for comprehensive universities, and only 3 were for postgraduates.

- There is a serious lack of empirical research on independent college students. There are only three studies on unsuccessful English learning.

- Meta-cognitive studies in other languages such as Spanish and German are almost nonexistent.

In view of the above problems, I believe that the second language learning metacognition research is also worth further in-depth and refinement, there are many questions worthy of foreign language colleagues to think and study, for example:

- What is the connotation of metacognition in the process of speaking and translation? How to integrate meta-cognitive content and metacognitive strategy training into specific teaching how is training mode?

- Is the choice of metacognitive strategies influenced by learners' personality?

- What is the relationship between metacognition in the field of metacognition and the emotions, wills, motives, motivations and gender of non-cognitive fields?
- How does cognitive strategy and metacognitive strategy interact and whether the combination of the two is more effective in promoting learning?

- What is the level of metacognition of English teachers at present? How is the metaphorical connotation of English teachers defined? Does the metacognitive level indirectly or directly affect the student's metacognitive ability?

- What is the specific role of metacognitive monitoring in the learning process? What are the specific factors of metacognitive level?

- How to combine the metacognitive theory and the principle of autonomous learning to construct a reasonable self - study model suitable for the needs of English majors?

- Does metacognitive theory apply to the process of learning in other languages?

\section{CONCLUSION}

In summary, although domestic scholars have fully studied and used metacognitive and metacognitive strategies to serve English teaching, the research in this field needs to be further developed in breadth and depth, especially how implementation of the metacognition research results in the practical teaching reform and how to evaluate its actual effect. English teaching staff needs to combine teaching practice with the characteristics of the students to conduct scientific experimental research to explore suitable and effective foreign language teaching model for our English learners.

\section{REFERENCES}

[1] Flavell J H, Metacognitive aspects of problem solving, In Resnick L B (Ed.). The Nature of Intelligence. Hillsdale N.J. Erlbaum, 1976.pp.231-236.

[2] Flavell $\mathrm{J} \mathrm{H}$, Metacognition and cognitive monitoring. A new area of cognitive-developmental inquiry. American Psychologist. 1979. vol. 34, pp. 906-911.

[3] Wenden A. Metacognitive knowledge and language learning. Applied Linguistics, 1998, (19/4). pp. 515-537.

[4] O'Malley J.M. \& Chamot A U. Learning Strategies in Second Language Acquisition. Cambridge: Cambridge University Press, 1990

[5] Oxford R L. Language Learning Strategies: What Every Teacher Should Know. Boston: Heinle \& Heinle, 1990.

[6] Wu Xia, Wang Qiang, Non-English majors' vocabulary learning strategies. Foreign Language Teaching and Research, 1998, vol.1.

[7] liu Peihua, Zhou Rong, Metacognition and Foreign language learning in Journal of Sichuan International Studies University, 1998, vol.4, pp $84-88$

[8] Liu Ying, A Study of Effectiveness on EFL Reading Metacognitive Strategy Training $[\mathrm{J}]$ Foreign Language Teaching and Research, 2009, vol.10.

[9] Xue Jin, Ineraction between L2 proficiency and metacognitive experience in reading training-a longitudinal study. Foreign Language World, 2011, vol.2.

[10] Tang Fang, Xu Jinfen. A Survey of Metacognition in English Writing at Home and Abroad, Foreign Language World. 2005, No.10. 
[11] Wu Hongyun, Liu Yunqing, A metacognitive framework for L2 writing: A factor analysis approach, Foreign Language Teaching and Research, May, 2004, No.3.

[12] Wu Hongyun, Liu Yunqing, Investigating the Effects of Metacognition in EFL Writing: A Structural Equation Modeling Approach, Modern Foreign Languages, Nov.2004, No.4.

[13] Wu Hongyun, An Empirical Study on Metacognitive Experiences in EFL Writing, Foreign Languages and Their Teaching, 2006, No.3.

[14] Han Song,An Empirical Study on the Functions of Metacognition in the EFL Writing of Non-English Major Graduates, Foreign Languages and Their Teaching,2008,No.10.

[15] Xu Jinfen, A Study of Differences in the Metacognitive Knowledge of Good and Poor English Writers, Journal of PLA University of Foreign Languages, 2007, No.6.

[16] Xiao Wuyun, An Empirical Study on Metacognitive Strategy Training Used to Improve Students' English Writing Performance, Journal of Sichuan International Studies University, Oct. 2011, No.5.

[17] Cai Hansong, Guo Jiayue, A Case Study of Psycholinguistics in Chinese Translation of Double Negative Sentences, Foreign Languages and Their Teaching, 2000, No.11.

[18] Tang Jianhe, On Metacognitive Monitoring in Translation Process, Journal of Sichuan International Studies University, 2007, vol.4.

[19] Liu Yuhui, Liu Xiaoyan, A Study on the Relationship between Metacognitive Strategies and Self-learning Ability of Non-English Majors, Foreign Language and Literature, Jun, 2013, No.3.

[20] Xiao Wuyun, Wang Xiaoping, Cao Qunying. An Empirical Study on Metacognitive Strategy Training Used in Improving Learner Autonomy and Language Achievement. Foreign Language Research, 2011, No.2:109-113.

[21] Yao Jianpeng. A Metacognitive Insight into Self-repair. Foreign Language Teaching, 2005, (3).

[22] Yao Jian-peng. An Insight into Feeling of Knowing in Speech SelfRepair. Journal of Sichuan International Studies University, 2012, (3). 